\title{
Clinical significance of melanoma cell adhesion molecule CD146 and VEGFA expression in epithelial ovarian cancer
}

\author{
PING ZHOU ${ }^{1}$, TINGCHUAN XIONG ${ }^{1}$, JINGXIN CHEN $^{2}$, FEN LI $^{1}$, TINGTING QI ${ }^{1}$ and JIANLIN YUAN $^{1}$ \\ ${ }^{1}$ Department of Gynecology and Obstetrics, Cancer Hospital Affiliated to Xinjiang Medical University, Wulumuqi, \\ Xinjiang 830011; ${ }^{2}$ Department of Gynaecology and Obstetrics, Dongfang Hospital Affiliated to Tongji University, \\ Shanghai 200120, P.R. China
}

Received November 7, 2017; Accepted October 26, 2018

DOI: $10.3892 / 01.2018 .9840$

\begin{abstract}
Ovarian cancer is the fifth most common type of cancer in females; however, its asymptomatic progression and the lack of an efficient screening strategy leads to late diagnosis. The present study aimed to investigate the expression levels of cluster of differentiation (CD)146 and vascular endothelial growth factor A (VEGFA) in epithelial ovarian cancer, and their clinical significance. A total of 52 ovarian samples were tested, of which 22 were from patients with epithelial ovarian cancer and 30 were from non-cancer patients. The relative gene expression of CD146 and VEGFA was quantified using reverse transcription-quantitative polymerase chain reaction analysis. Western blotting was used to determine the protein expression levels. The relative gene expression levels of CD146 and VEGFA in tumor tissues were significantly increased compared with the control $(4.92 \pm 0.44$ vs. $1.05 \pm 0.06$ and $3.08 \pm 0.17$ vs. $1.06 \pm 0.07, \mathrm{P}<0.01)$. The protein expression levels of CD146 and VEGFA in tumor tissue were also significantly increased compared with the control $(0.70 \pm 0.02$ vs. $0.41 \pm 0.07$ and $0.54 \pm 0.01$ vs. $0.26 \pm 0.01, \mathrm{P}<0.01)$. There was a positive correlation between the expression levels of CD146 and VEGFA genes $(r=0.78)$ and between the two proteins $(r=0.69)$. Dot density frequency analysis indicated that CD146 and VEGFA were specifically present in tumor tissues. In conclusion, CD146 and VEGFA are co-overexpressed in ovarian cancer; their potential as tumor biomarkers or therapeutic targets for the treatment of ovarian cancer requires further investigation.
\end{abstract}

Correspondence to: Dr Jianlin Yuan, Department of Gynecology and Obstetrics, Cancer Hospital Affiliated to Xinjiang Medical University, 789 Suzhoudong Street, Wulumuqi, Xinjiang 830011, P.R. China

E-mail: jlyuan128@yeah.net

Key words: ovarian cancer, cluster of differentiation 146, vascular endothelial growth factor-A, reverse transcriptionquantitative-polymerase chain reaction, western blotting

\section{Introduction}

Ovarian cancer, the leading cause of mortality among gynecological malignancies, is the fifth most common type of cancer in females $(1,2)$. The majority of patients with ovarian cancer are diagnosed at a late tumor stage, due to the asymptomatic progression and lack of an efficient screening strategy (3). High-grade serous ovarian cancers exhibit frequent tumor protein p53 (TP53) mutations, whereas GTPase KRAS and serine/threonine-protein kinase B-raf mutations are less common (4). Melanoma cell adhesion molecule, also termed cluster of differentiation 146 (CD146), and vascular endothelial growth factor A (VEGFA) are frequently studied angiogenic factors in other cancer types, and are considered to be important in the progression of cancer (5).

Tumor growth and metastasis depend on angiogenesis, which provides oxygen and nutrients to tumor cells (6). CD146 is a non-CA ${ }^{2+}$-dependent cell adhesion molecule on the cell membrane surface of transmembrane glycoproteins, and is involved in neovascularization (7-11). The mechanism of CD146-regulated tumor angiogenesis may involve the activation of matrix metalloproteinase-2 via VEGFA, leading to extracellular matrix degradation, angiogenesis and metastasis (12). CD146 on tumor endothelial cells binds the CD146 ligand on tumor cells to cause cell aggregation, vessel blocking and adhesion to new vascular endothelia. These processes all lead to tumor invasion and metastasis (10,13-21).

The biological functions of angiogenesis in ovarian cancer development remain unknown; there are contradictory studies regarding the influence of microvessel density in ovarian cancer prognosis (22-24). Certain studies report that there is no a clear association between VEGFA and prognosis $(25,26)$, whereas others have demonstrated a considerable independent prognostic influence (27). The abilities of sprouting, migration and tube formation in response to VEGFA treatment are impaired in the endothelial cells (ECs) of CD146 EC-knockout (KO) mice. Mechanistic studies further illustrated that VEGFA-induced VEGF receptor (VEGFR)-2 phosphorylation and RAC- $\alpha$ serine/threonine-protein kinase (Akt)/p38 mitogen-activated protein kinase/nuclear factor- $\kappa \mathrm{B}$ pathway activation were inhibited in these CD146-null endothelial cells, which may indicate the underlying reason for the observed tumor angiogenesis inhibition in CD146EC-KO mice (26). Knockdown of 
CD146 decreased VEGFR-2/E-cadherin expression and altered focal adhesion kinase activation in response to VEGF (28).

VEGFA, a primary responder to VEGF signaling, serves important roles in physiological and pathological angiogenesis. Tumors which grow quickly generally have increased numbers of interstitial blood vessels and less fibrous connective tissue compared with benign tumors that grow slowly (29). The induction of neovascularization is one of the prerequisites for tumor growth, invasion and metastasis.

Recently, CD146 has been identified as a VEGFR-2 coreceptor-mediated VEGF/VEGFR2 pathway that is essential in VEGF-induced cell migration and tube formation, and has been implicated in the tumor progression of epithelial ovarian cancer $(30,31)$. The present study aimed to characterize the expression pattern of CD146 and VEGFA in ovarian cancer and their role in this cancer type.

\section{Materials and methods}

Patients. Epithelial ovarian samples were collected $<10 \mathrm{~min}$ following surgery from 22 patients with ovarian cancer, including 14 cases of high-grade serous ovarian carcinoma, eight cases of low-grade serous ovarian carcinoma and 30 cases diagnosed with benign disease (control) between January 2014 and January 2016, in the Cancer Hospital Affiliated to Xinjiang Medical University (Xinjiang, China). Among them, four cases were $<30$ years old, 21 were between 30 and 40 years, nine patients were between 40 and 50 years, 14 were between 50 and 60 years and four cases were $>60$ years. The median age was 50.1 years. A total of 12 patients had lymph node metastasis. All specimens collected prior to chemotherapy, radiation therapy or immunotherapy were histopathologically confirmed to be epithelial ovarian cancer. Informed consent was obtained from all individual participants included in the study, and the study was approved by the ethics committee of the Cancer Hospital Affiliated to Xinjiang Medical University.

Reagents and instruments. TRIzol ${ }^{\circledR}$ was purchased from Invitrogen (Thermo Fisher Scientific, Inc., Waltham, MA, USA); the high-efficiency reverse transcription (RT) kit was purchased from Tiangen Biotech Co., Ltd. (Beijing, China) and SYBR Select Master mix was purchased from Applied Biosystems (Thermo Fisher Scientific, Inc.) VEGFA and GAPDH primers (Table I) were synthesized by Quintarabio Biotechnology Co., Ltd. (Urumqi, China), and the RT-quantitative polymerase chain reaction (RT-qPCR) instrument was purchased from Applied Biosystems.

$R T$ - $q P C R$. RNA extraction was conducted using TRIzol ${ }^{\circledR}$, according to the manufacturer's protocol. Briefly, $100 \mathrm{mg}$ homogenized tissue samples were mixed with $800 \mu 1$ TRIzol and $200 \mu \mathrm{l}$ chloroform. The mixture was vortexed thoroughly for $2 \mathrm{~min}$, incubated for $20 \mathrm{~min}$ at room temperature, and centrifuged at $8,000 \mathrm{x}$ g for $20 \mathrm{~min}$ at $4^{\circ} \mathrm{C}$. The upper phase was carefully transferred into a fresh tube, and precipitated with $600 \mu \mathrm{l}$ isopropanol at $-20^{\circ} \mathrm{C}$ for $20 \mathrm{~h}$. Following centrifugation, the RNA pellet was washed with $70 \%$ ethanol, air dried and re-suspended in $1 \mathrm{ml}$ diethyl pyrocarbonate-treated water. cDNA was transcribed using $500 \mathrm{ng}$ RNA as the template, according to the RT kit instructions, and stored at $-80^{\circ} \mathrm{C}$.
Each RT-qPCR reaction tube contained 12.5 $\mu$ 1 SYBR Green Real-time PCR Master mix, $1 \mu \mathrm{l}$ of each forward and

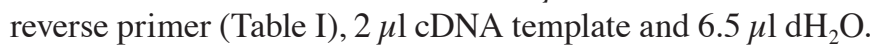
The mixture was centrifuged for $15 \mathrm{sec}$, and RT-qPCR was performed using the following protocol: An initial denaturation step at $95^{\circ} \mathrm{C}$ for 2 min, 40 cycles of amplification with denaturation at $95^{\circ} \mathrm{C}$ for $15 \mathrm{sec}$, and annealing and extension at $60^{\circ} \mathrm{C}$ for $1 \mathrm{~min}$. PCR signals from a total of 40 cycles were collected at $60^{\circ} \mathrm{C}$ and fluorescence quantitation was assessed using RT-qPCR software.

The relative expression levels of target genes were quantified by normalizing target gene expression to that of the internal control using the $2^{-\Delta \Delta \mathrm{Cq}}$ formula (32).

Measuring the protein expression levels of CD146 and VEGFA using western blotting. Proteins from ovarian tissues were extracted using radioimmunoprecipitation assay/phenylmethylsulfonyl fluoride (100:1) solution, according to the manufacturer's instructions (Boster Biological Technology, Pleasanton, CA, USA). A total of $50 \mu \mathrm{g}$ proteins (concentration $2.5 \mu \mathrm{g} / \mu \mathrm{l}$ ) were electro-separated on a $10 \%$ SDS-PAGE gel and electro-transferred onto a polyvinylidene difluoride membrane (EMD Millipore, Billerica, MA, USA) for western blotting. The membrane was rinsed with PBS and the non-specific binding sites were blocked in a solution of $5 \%$ non-fat milk in PBS with $0.05 \%$ Tween-20 (PBST) for $2 \mathrm{~h}$ at $37^{\circ} \mathrm{C}$, followed by three washes with PBST. The primary antibodies against CD146 (1:500 dilution; cat. no. 13475S; CST Biological Reagents Co., Ltd., Shanghai, China), VEGFA (1:1,000 dilution; cat. no. 2478S; CST Biological Reagents Co., Ltd.) and $\beta$-actin (1:2,500 dilution; cat. no. ab8227; Abcam, Cambridge, UK) were added and incubated overnight at $4^{\circ} \mathrm{C}$. The secondary Goat Anti-Rabbit-IgG $(\mathrm{H}+\mathrm{L})$ antibody conjugated to horseradish peroxidase (1:10,000 dilution; cat. no. 31460; Pierce; Thermo Fisher Scientific Inc.) was added for a 1-h incubation at room temperature. Western blotting signals were developed using an enhanced chemiluminescent kit (cat. no. 32106; Thermo Fisher Scientific, Inc.). Following color development, the detection of immunoreactive bands was performed using a ChemiScope mini chemiluminescence meter (Qinxiang Science Instrument Co., Ltd., Shanghai, China).

The protein expression levels were calculated using the following equation: Protein expression=integral optical density value of target protein/integral optical density value of $\beta$-actin. Protein levels were quantified using a ChemiScope Mini system (Qinxiang Science Instrument Co., Ltd.).

Immunohistochemistry (IHC). Tissue samples were fixed with $4 \%$ paraformaldehyde at room temperature for $12 \mathrm{~h}$ and embedded with paraffin. Following deparaffinization and rehydration, the CD146 and VEGFA antigens were

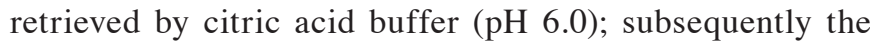
samples were blocked for endogenous peroxidase activity using 3\% hydrogen peroxide (Sigma-Aldrich; Merck KGaA, Darmstadt, Germany) for $30 \mathrm{~min}$ at $37^{\circ} \mathrm{C}$ and then $2 \mathrm{~min}$ at room temperature. Following washing with potassium-free PBS buffer, the samples were incubated with monoclonal antibodies against CD146 (catalog no. ab75769; 1:100; Abcam) and VEGFA (catalog no. ab51745; 1:100; Abcam) overnight 
Table I. Primers used for reverse transcriptase-quantitative polymerase chain reaction.

\begin{tabular}{ccc}
\hline Gene & Primer sequence $\left(5^{\prime} \rightarrow 3^{\prime}\right)$ & $\begin{array}{c}\text { Amplicon } \\
\text { size } \\
\text { (base pairs) }\end{array}$ \\
\hline CD146 F: AGCTCCGCGTCTACAAAGC & 102 \\
& $\begin{array}{l}\text { R: CTACACAGGTAGCGACCTCC } \\
\text { VEGFA F: AGGGCAGAATCATCACGAAGT }\end{array}$ & 75 \\
& $\begin{array}{l}\text { R: AGGGTCTCGATTGGATGGCA } \\
\text { GAPDH F: GGAGCGAGATCCCTCCAAAAT }\end{array}$ & 197 \\
& R: GGCTGTTGTCATACTTCTCATGG & \\
\end{tabular}

$\mathrm{F}$, forward primer; $\mathrm{R}$, reverse primer; $\mathrm{CD}$, cluster of differentiation; VEGFA, vascular endothelial growth factor $\mathrm{A}$.

at $4^{\circ} \mathrm{C}$. Following rewarming, the samples were incubated with the corresponding secondary antibody (Goat Anti-Rabbit-IgG $(\mathrm{H}+\mathrm{L})$ antibody conjugated to horseradish peroxidase; cat. no. 31460; 1:1,000; Pierce) for $1 \mathrm{~h}$ at room temperature. The sections were subsequently stained with Mayer's hematoxylin for $5 \mathrm{~min}$ at room temperature, followed by dehydration and permeabilization. Finally, the sections were mounted with neutral resins and visualized by light microscopy (x100 magnification). Staining intensity was graded as 0 (negative), 1 (weak), 2 (moderate), and 3 (strong); the percentage of positive cells examined was scored as 0 (negative), $1(<10 \%)$, 2 (11-50\%), $3(51-80 \%)$, and $4(>80 \%)$. The two scores were multiplied and the immunoreactivity score (IRS; values of $0-12)$ was determined: Values $0-1$ as negative (-); 2-3 as weak positive (+); values $4-8$ as moderate positive $(++)$; and values 9-12 as strongly positive (+++).

Statistical analysis. Statistical analysis was performed using SPSS version 17.0 (SPSS Inc., Chicago, IL, USA). Data are presented as the mean \pm standard deviation. All experiments were repeated three times. Student's t-test was used to compare the means of two independent groups in order to determine whether differences between the means were significant. The Pearson test used for the independent data revealed the associations among the factors tested. A Spearman's Rho test was used to determine the correlation between the IRS of CD146 and VEGFA and the pathological grade of tumor IRS, and the statistical significance of differences between tumor tissues and non-tumor tissues. Dot density frequency analysis, using SigmaPlot 11.1.0 (Systat Software Inc., San Jose, CA, USA), was performed on the means of CD146 and VEGFA to assess their sensitivity and specificity $(33,34) . \mathrm{P}<0.05$ was considered to indicate a statistically significant difference.

\section{Results}

Gene and protein expression levels of CD146 and VEGFA in ovarian tissues. The RT-qPCR results demonstrated that CD146 and VEGFA gene expression levels in the primary tumor were significantly increased compared with the control (CD146 4.92 \pm 0.44 vs. $1.05 \pm 0.06, \mathrm{P}<0.01$; VEGFA,

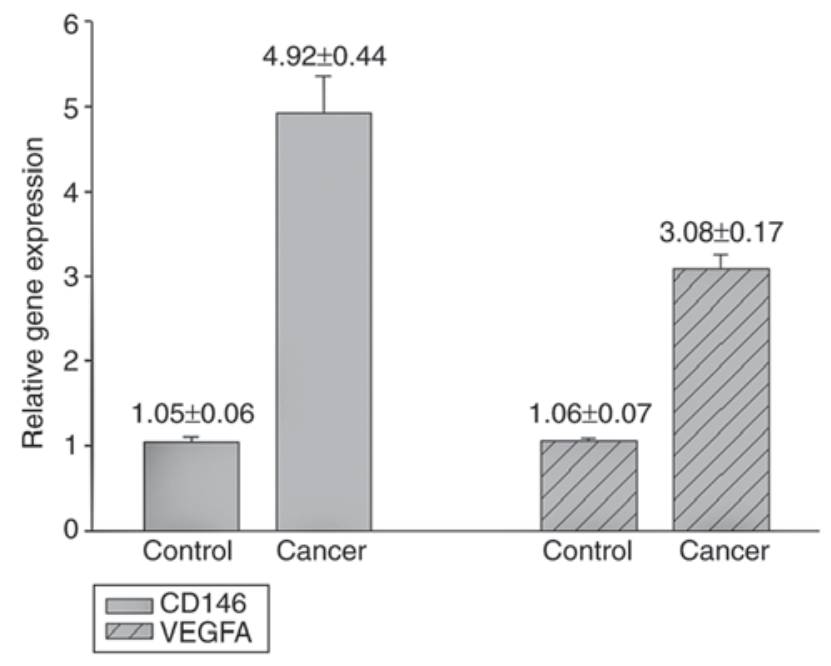

Figure 1. Relative gene expression of CD146 and VEGFA in ovarian cancer tissues vs. control tissues. CD, cluster of differentiation; VEGFA, vascular endothelial growth factor A.

$3.08 \pm 0.17$ vs. $1.06 \pm 0.07, \mathrm{P}<0.01$; Fig. 1$)$. The results of the western blotting experiments indicated that the protein expression levels of CD146 and VEGFA in the primary tumors were significantly higher compared with those of the control (CD146 protein, $0.70 \pm 0.02$ vs. $0.41 \pm 0.07, \mathrm{P}<0.01$; VEGFA protein, $0.54 \pm 0.01$ vs. $0.26 \pm 0.01, \mathrm{P}<0.01$; Fig. 2 ).

Correlation analysis. The Pearson correlation analysis (Table II) demonstrated that there were significant positive correlations between the gene and protein expression levels of CD146 ( $\mathrm{r}=0.73, \mathrm{P}<0.05)$, gene and protein expression levels of VEGFA ( $r=0.74, \mathrm{P}<0.05)$, gene expression levels of CD146 and VEGFA ( $\mathrm{r}=0.78, \mathrm{P}<0.05)$, protein expression levels of CD146 and VEGFA ( $r=0.69, \mathrm{P}<0.05), \mathrm{CD} 146$ gene expression levels and VEGFA protein expression levels $(r=0.77, \mathrm{P}<0.05)$ and between CD146 protein expression levels and VEGFA gene expression levels $(r=0.81, \mathrm{P}<0.05)$. Although the results of IHC demonstrated that the protein expression levels of CD146 (IRS=8) and VEGFA (IRS=9) in tumor tissue were significantly higher compared with those in non-tumor tissue (IRS=2, Fig. 3), the Spearman's Rho value was 0.37, indicating no strong association between the IRS of CD146 and VEGFA and the pathological grade of the tumor $(\mathrm{P}>0.05$; data not shown).

Dot density frequency analysis. The optimal cut off values determined by dot density frequency analysis were 1.80 and 1.96 for the CD146 and VEGFA gene expression levels, respectively (Fig. 4), and 0.55 and 0.45 for the CD146 and VEGFA protein expression levels, respectively (Fig. 5).

\section{Discussion}

Expression of CD146 and VEGFA is necessary for tumor occurrence and development. CD146 promotes cancer progression, enhanced migration and invasion in melanoma, gallbladder adenocarcinoma, breast cancer and prostate cancer $(6,35)$. It has been recognized as a biomarker to predict poor prognosis in gastric cancer, lung adenocarcinoma, malignant pleural 
Table II. Pearson correlation coefficients (r) between the gene and protein expression of CD146 and VEGFA.

\begin{tabular}{|c|c|c|c|c|}
\hline & $\begin{array}{c}\text { CD146 } \\
\text { gene expression }\end{array}$ & $\begin{array}{c}\text { CD146 } \\
\text { protein expression }\end{array}$ & $\begin{array}{c}\text { VEGFA } \\
\text { gene expression }\end{array}$ & $\begin{array}{c}\text { VEGFA } \\
\text { protein expression }\end{array}$ \\
\hline CD146 gene expression & 1 & - & - & - \\
\hline CD146 protein expression & $0.73^{\mathrm{a}}$ & 1 & - & - \\
\hline VEGFA gene expression & $0.78^{\mathrm{a}}$ & $0.81^{\mathrm{a}}$ & 1 & - \\
\hline VEGFA protein expression & $0.77^{\mathrm{a}}$ & $0.69^{\mathrm{a}}$ & $0.74^{\mathrm{a}}$ & 1 \\
\hline
\end{tabular}

${ }^{\mathrm{a}} \mathrm{P}<0.05$. CD, cluster of differentiation; VEGFA, vascular endothelial growth factor A.
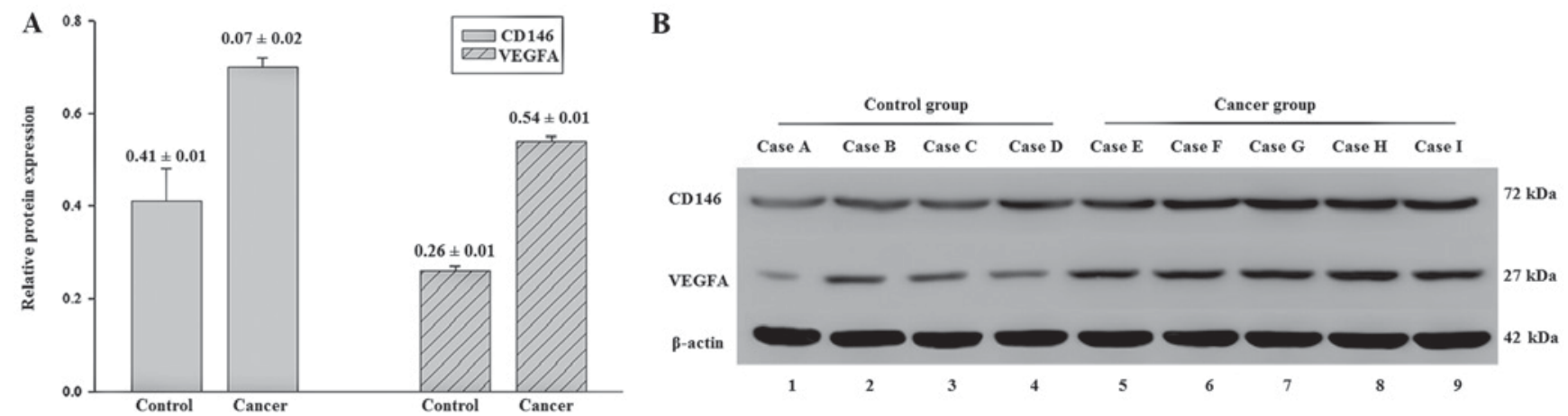

Figure 2. Relative protein expression levels of CD146 and VEGFA, determined via western blotting. (A) Relative protein expression levels of CD146 and VEGFA in ovarian cancer tissues vs. control tissues. (B) Western blot image of CD146 and VEGFA expression levels in ovarian cancer tissues vs. control tissues. Lanes 1 to 4 , four different representative samples from patients without ovarian cancer (control group); lanes 5 to 9 , five different representative samples from patients with ovarian cancer (cancer group). CD, cluster of differentiation; VEGFA, vascular endothelial growth factor A.
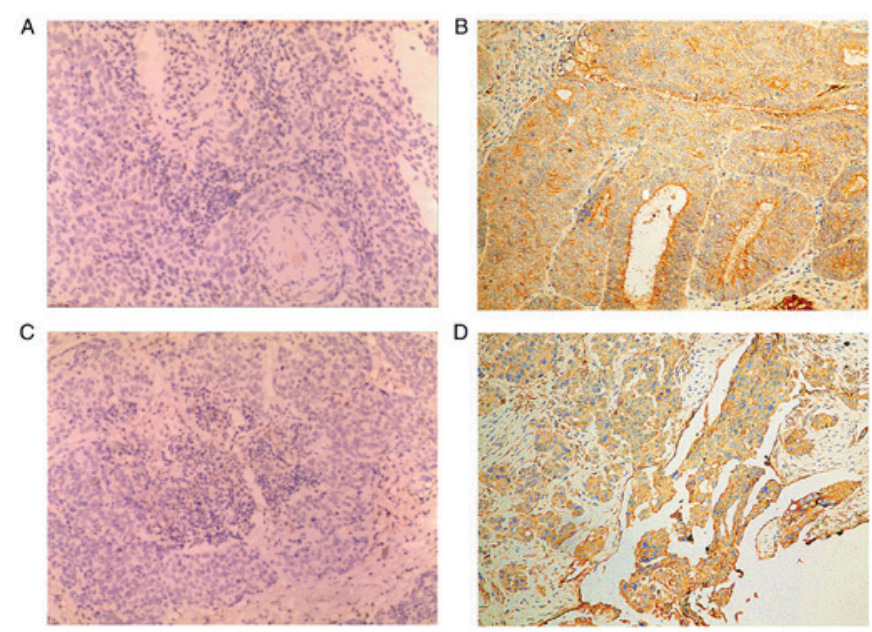

Figure 3. Images of immunohistochemistry staining for positive protein expression (brown). Magnification, x100. (A) CD146 protein expression in non-ovarian cancer tissues. (B) CD146 protein expression in ovarian cancer tissues. (C) VEGFA protein expression in non-ovarian cancer tissues. (D) VEGFA protein expression in ovarian cancer tissues. CD, cluster of differentiation; VEGFA, vascular endothelial growth factor A.

mesothelioma and non-small-cell lung cancer (36-39). CD146 is associated with an advanced tumor stage in melanoma, prostate cancer and ovarian cancer (6). Inhibition of CD146 gene expression via RNA interference reduces in vitro perineural invasion in a high-metastatic adenoid cystic carcinoma cell line (ACC-M) (40). In triple-negative breast

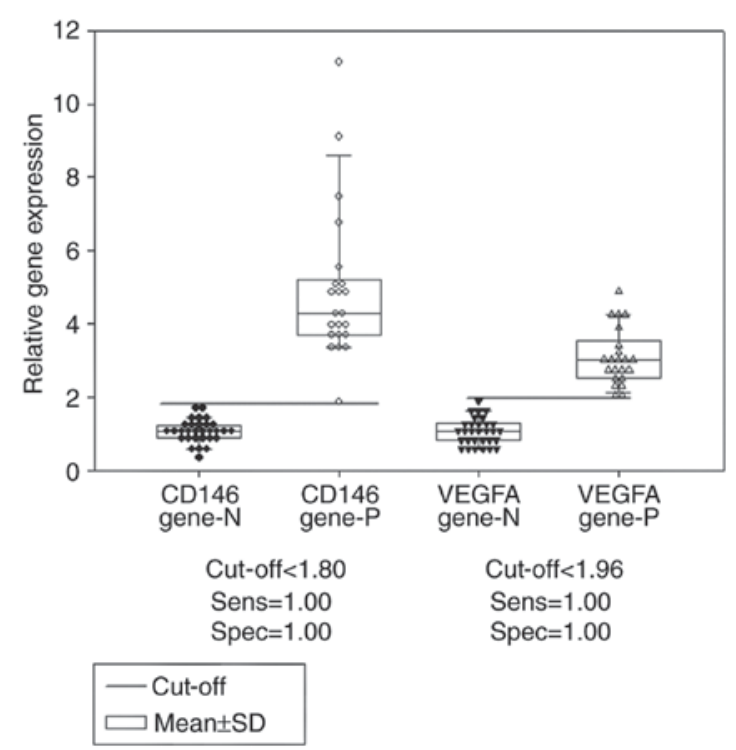

Figure 4. Comparison of the gene expression levels of CD146 and VEGFA in ovarian tissues between patients with and without epithelial ovarian cancer, using dot density frequency. The cut-off values of CD146 and VEGFA gene expression were 1.80 and 1.96, respectively. CD146 gene-N, CD146 gene expression in the control; CD146 gene-P, CD146 gene expression in patients with cancer; VEGFA gene-N, VEGFA gene expression in the control; VEGFA gene-P, VEGFA gene expression in patients with cancer. $\mathrm{CD}$, cluster of differentiation; VEGFA, vascular endothelial growth factor $\mathrm{A}$; SD, standard deviation.

cancer samples, high expression levels of CD146 are strongly associated with E-cadherin downregulation, suggesting that 


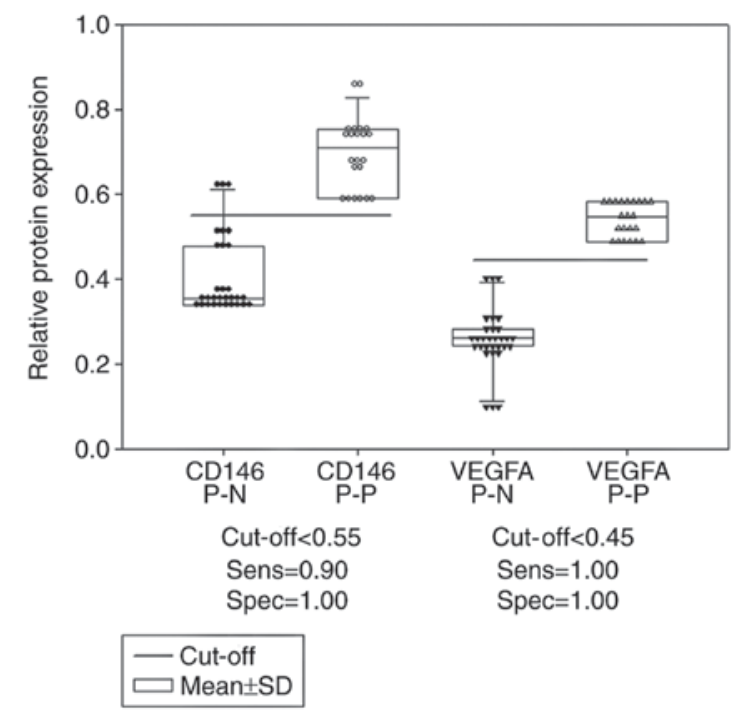

Figure 5. Comparison of the protein expression levels of CD146 and VEGFA in ovarian tissues between patients with and without epithelial ovarian cancer, using dot density frequency. The cut-off value of CD146 protein expression was 0.55 ; the cut-off value of VEGFA protein expression was 0.45 . CD146 $\mathrm{P}-\mathrm{N}, \mathrm{CD} 146$ protein expression in the control; CD146 P-P, CD146 protein expression in patients with cancer; VEGFA P-N, VEGFA protein expression in the control; VEGFA P-P, VEGFA protein expression in patients with cancer. CD, cluster of differentiation; VEGFA, vascular endothelial growth factor $\mathrm{A} ; \mathrm{SD}$, standard deviation.

CD146 promotes breast cancer progression due to the induction of epithelial-mesenchymal transition via the activation of ras homolog family member $\mathrm{A}$ and the upregulation of snail family transcriptional repressor 2 (41). A CD146 immunohistochemical study revealed that its overexpression was positively and significantly correlated with the pathological subtype of cervical cancer, with the histological grade and depth of myometrial invasion in endometrial cancer, yet not with patient age or the pathological type of the tumor (42).

VEGFA expression in patients with ovarian cancer at stages III and IV is significantly higher compared with that at stages I and II (43). VEGFA represents a potent cytokine in ovarian cancer progression. High VEGFA production from primary tumors was hypothesized to correlate with increased metastasis and a worse prognosis compared with low VEGFA-producing tumors (44). In addition, VEGFA secretion has recently been proposed as one of the major factors responsible for defective immune function in patients with cancer (44). Patients with early-stage cancer (stages I and II) display a poorer prognosis when VEGFA expression is increased in the tumor (45), and elevated expression levels of the VEGFA gene predict a poor prognosis; notably, this does not appear to be associated with microvessel density, which contradicts previous studies $(25,45)$. A tissue microarray study indicated that high VEGFA expression levels in epithelial ovarian cancer may be associated with serous morphology, high grade and advanced stage. Among 78 cases of primary malignant epithelial ovarian neoplasms that exhibited high VEGFA expression, 23 were serous carcinomas (46).

The present study confirmed that the gene and protein expression levels of CD146 and VEGFA in cancer tissues were increased significantly, and were positively correlated with each other. Dot density frequency analysis revealed that gene expression levels of CD146 and VEGFA are superior compared with protein expression levels as potential biological indicators. Furthermore, protein quantification is costly and time-consuming. The cut off value of the gene expression levels, based on the mean, were higher compared with the control, indicating that a gene expression approach may be used in the first instance.

The Pearson test was used to compare the gene/gene, gene/protein and protein/protein expression levels, and it was confirmed that CD146 and VEGFA are co-expressed, yet their expression levels in the tumor tissue are not associated with pathological grade of ovarian serous carcinomas. This result is consistent with the results of Premalata et al (47), as the results of that study suggested that the high expression levels of VEGFA in epithelial ovarian cancer may be associated with serous morphology, high grade and advanced stage. Though a certain level of VEGFA expression was observed in the majority of ovarian carcinomas, high expression levels were only observed in one-third of patients. High VEGFA expression levels occurred in a small proportion of patients with ovarian cancer, and this may be used as an independent predictor of poor prognosis; patients with tumors that express high levels of VEGFA had worse survival rates compared with those with medium, low or no VEGFA expression (48).

Spearman's Rho analysis failed to suggest that the overexpression of CD146 and VEGFA was associated with high histopathological grade. In fact, it was only associated with static changes in the tumor, including the tumor size, growth rate, infiltration and metastatic progression in contrast to dramatic changes. CD146 interacts with VEGF-C directly to control lymphatic sprouting in lymphangiogenesis. CD146 is expressed in lymphatic endothelial cells (LEC) and regulates LEC activation induced by VEGF-C. It has been demonstrated in vitro and in vivo that CD146 is a receptor of VEGF-C, regulating lymphangiogenesis at the sprouting step independently of vasculogenesis (49).

CD146 and VEGFA expression levels are directly associated with dynamic tumor behavior. Thus, to a certain extent, these factors influence the biological status (proliferation or inhibition) of the tumor cells in the body; therefore, they are more likely to be the dynamic indicators of tumor alterations, including the potential growth rate, prognosis and the effects of anticancer agents (6). All of these will provide an important reference value in the clinic.

In a xenograft model using immunodeficient NOD/Shi-scid IL-2R $\gamma$-null mice, $\mathrm{CD}_{146^{+}}$cells purified from malignant rhabdoid tumor (MRT) cell lines or a primary tumor displayed the unique ability to form tumors in vivo. Blocking CD146-associated mechanisms, including short hairpin RNA knockdown or treatment with a polyclonal antibody against CD146, effectively suppressed the tumor growth of MRT cells in vitro and in vivo, via the induction of apoptosis by inactivating Akt (50).

CD146 and VEGFA cut-off values determined from dot density frequency may predict the biological status of tumor cells based on sensitivity and specificity. Analysis of the dot density graphs indicated that for the identification of ovarian cancer and the control group, the cut-off for the gene expression was 1.80 (CD146) and 1.96 (VEGFA) respectively; the cut-off for the protein expression was 0.55 (CD146) and 
0.45 (VEGFA) respectively. It was postulated that elevated cellular production of CD146 and VEGFA may serve as a potential indicator of tumor alterations, and that these factors may correlate with a poorer prognosis for patients with ovarian carcinoma. These indicators may facilitate the investigation of whether tumor cells are under either proliferative or inhibitory conditions. VEGFA is a key regulator of angiogenesis, which drives endothelial cell survival, proliferation and migration while increasing vascular permeability. VEGFA not only serves an important function in the physiology of normal ovaries, but has also been implicated in the pathogenesis of ovarian cancer. It is understood that CD146 serves a potent role in angiogenesis, and VEGFA may also serve a central and specific function in angiogenesis (51).

In conclusion, CD146 and VEGFA expression levels are positively correlated with dynamic tumor biology, and they are co-overexpressed in ovarian cancer as indicators of tumor activity. Their expression levels may be important indicators in the diagnosis, treatment and prognosis of epithelial ovarian cancer.

\section{Acknowledgements}

Not applicable.

\section{Funding}

The present study was funded by grant no. Y14130032, from the Science and Technology Board of Wulumuqi City. Project name: Study on the correlation between CD146, VEGF-A and the invasion and metastasis of epithelial ovarian cancer; local level.

\section{Availability of data and materials}

The datasets used and/or analyzed during the current study are available from the corresponding author on reasonable request.

\section{Authors' contributions}

PZ and JY conceived the study, designed the experiments and wrote the manuscript. PZ, TX, JC and FL performed laboratory tests and acquired the data. TQ analyzed the data and performed the statistical analysis. JY conducted a literature search and gave suggestions on revising the manuscript.

\section{Ethics approval and consent to participate}

All procedures performed in studies involving human participants were in accordance with the ethical standards of the institutional and/or national research committee and with the 1964 Helsinki declaration and its later amendments or comparable ethical standards. Informed consent was obtained from all individual participants included in the study, and the study was approved by the Ethics Committee of the Cancer Hospital Affiliated to Xinjiang Medical University.

\section{Patient consent for publication}

Consent to the publication of material was obtained from all participants included in the study.

\section{Competing interests}

The authors declare that they have no competing interests.

\section{References}

1. Jemal A, Bray F, Center MM, Ferlay J, Ward E and Forman D: Global cancer statistics. CA Cancer J Clin 61: 69-90, 2011.

2. Bowtell DD: The genesis and evolution of high-grade serous ovarian cancer. Nat Rev Cancer 10: 803-808, 2010.

3. Bast RC Jr, Hennessy B and Mills GB: The biology of ovarian cancer: New opportunities for translation. Nat Rev Cancer 9: 415-428, 2009.

4. Rechsteiner M, Zimmermann AK, Wild PJ, Caduff R, von Teichman A, Fink D, Moch H and Noske A: TP53 mutations are common in all subtypes of epithelial ovarian cancer and occur concomitantly with KRAS mutations in the mucinous type. Exp Mol Pathol 95: 235-241, 2013.

5. Friedlander LT, Hussani H, Cullinan MP, Seymour GJ, De Silva RK, De Silva H, Cameron C and Rich AM: VEGF and VEGFR2 in dentigerous cysts associated with impacted third molars. Pathology 47: 446-451, 2015.

6. Zabouo G, Imbert AM, Jacquemier J, Finetti P, Moreau T, Esterni B, Birnbaum D, Bertucci F and Chabannon C: CD146 expression is associated with a poor prognosis in human breast tumors and with enhanced motility in breast cancer cell lines. Breast Cancer Res 11: R1, 2009.

7. Shih IM: The role of CD146 (Mel-CAM) in biology and pathology. J Pathol 189: 4-11, 1999.

8. Yan X, Lin Y, Yang D, Shen Y, Yuan M, Zhang Z, Li P, Xia H, Li L, Luo D, et al: A novel anti-CD146 monoclonal antibody, AA98, inhibits angiogenesis and tumor growth. Blood 102: 184-191,2003.

9. Wu GJ, Varma VA, Wu MW, Wang SW, Qu P, Yang H, Petros JA, Lim SD and Amin MB: Expression of a human cell adhesion molecule, MUC18, in prostate cancer cell lines and tissues. Prostate 48: 305-315, 2001.

10. Bardin N, Anfosso F, Massé JM, Cramer E, Sabatier F, Le Bivic A, Sampol J and Dignat-George F: Identification of CD146 a component of the endothelial junction involved in the control of cell-cell cohesion. Blood 98: 3677-3684, 2001.

11. Kang Y, Wang F, Feng J, Yang D, Yang X and Yan X: Knockdown of CD146 reduces the migration and proliferation of human endothelial cells. Cell Res 16: 313-318, 2006.

12. Campbell NE, Kellenberger L, Greenaway J, Moorehead RA, Linnerth-Petrik NM and Petrik J: Extracellular matrix proteins and tumor angiogenesis. J Oncol 2010: 586905, 2010.

13. Vainio O, Dunon D, Aïssi F, Dangy JP, McNagny KM and Imhof BA: HEMCAM, an adhesion molecule expressed by c-kit+ hemopoietic progenitors. J Cell Biol 135: 1655-1668, 1996.

14. Bowen MA, Patel DD, Li X, Modrell B, Malacko AR, Wang WC, Marquardt H, Neubauer M, Pesando JM, Francke U, et al: Cloning, mapping, and characterization of activated leukocyte-cell adhesion molecule (ALCAM), a CD6 ligand. J Exp Med 181: 2213-2220, 1995.

15. Anfosso F, Bardin N, Francès V, Vivier E, Camoin-Jau L, Sampol J and Dignat-George F: Activation of human endothelial cells via S-endo 1 antigen (CD146) stimulates the tyrosine phosphorylation of focal adhesion kinase p125(FAK). J Biol Chem 273: 26852-26856, 1998.

16. Bardin N, Francès V, Combes V, Sampol J and Dignat-George F: CD146: Biosynthesis and production of a soluble form in human cultured endothelial cells. FEBS Lett 421: 12-14, 1998.

17. Kang Y, Wang F, Feng J, Yang D, Yang X and Yan X: Knockdown of CDl46 reduces the migration and proliferation of human endothelial cells. Cell Res 16: 313-318, 2006.

18. Schrage A, Loddenkemper C, Erben U, Lauer U, Hausdorf G, Jungblut PR, Johnson J, Knolle PA, Zeitz M, Hamann A and Klugewitz K: Murine CD146 is widely expressed on endothelial cells and is recognized by the monoclonal antibody ME-9F1. Histochem Cell Biol 129: 441-451, 2008.

19. Bardin N, Blot-Chabaud M, Despoix N, Kebir A, Harhouri K, Arsanto JP, Espinosa L, Perrin P, Robert S, Vely F, et al: CD146 and its soluble form regulate monocyte transendothelial migration. Arterioscler Thromb Vasc Biol 29: 746-753, 2009.

20. Zheng C, Qiu Y, Zeng Q, Zhang Y, Lu D, Yang D, Feng J and Yan X: Endothelial CD146 is required for in vitro tumor-induced angiogenesis: The role of a disulfide bond in signaling and dimerization. Int J Biochem Cell Bio 41: 2163-2172, 2009. 
21. Satyamoorthy K, Muyrers J, Meier F, Patel D and Herlyn M: Mel-CAM-specific genetic suppressor elements inhibit melanoma growth and invasion through loss of gap junctional communication. Oneogene 20: 4676-4684, 2001.

22. Hollingsworth HC, Kohn EC, Steinberg SM, Rothenberg ML and Merino MJ: Tumor angiogenesis in advanced stage ovarian carcinoma. Am J Pathol 147: 33-41, 1995.

23. Gasparini G, Bonoldi E, Viale G, Verderio P, Boracchi P, Panizzoni GA, Radaelli U, Di Bacco A, Guglielmi RB and Bevilacqua P: Prognostic and predictive value of tumor angiogenesis in ovarian carcinomas. Int J Cancer 69: 205-211, 1996.

24. Orre M, Lotfi-Miri M, Mamers P and Rogers PA: Increased microvessel density in mucinous compared with malignant serous and benign tumours of the ovary. Br J Cancer 77: 2204-2209, 1998.

25. Nakanishi Y, Kodama J, Yoshinouchi M, Tokumo K, Kamimura S, Okuda H and Kudo T: The expression of vascular endothelial growth factor and transforming growth factor-beta associates with angiogenesis in epithelial ovarian cancer. Int J Gynecol Pathol 16: 256-262, 1997.

26. Yamamoto S, Konishi I, Mandai M, Kuroda H, Komatsu T, Nanbu K, Sakahara H and Mori T: Expression of vascular endothelial growth factor (VEGF) in epithelial ovarian neoplasms: Correlation with clinicopathology and patient survival, and analysis of serum VEGF levels. Br J Cancer 76: 1221-1227, 1997.

27. Komatsu H, Oishi T, Itamochi H, Shimada M, Sato S, Chikumi J, Sato S, Nonaka M, Sawada M, Wakahara M, et al: Serum vascular endothelial growth factor-A as a prognostic biomarker for epithelial ovarian cancer. Int J Gynecol Cancer 27: 1325-1332, 2017.

28. Jouve N, Bachelier R, Despoix N, Blin MG, Matinzadeh MK, Poitevin S, Aurrand-Lions M, Fallague K, Bardin N, Blot-Chabaud M, et al: CD146 mediates VEGF-induced melanoma cell extravasation through FAK activation. Int J Cancer 137: 50-60, 2015.

29. Wang W, Yang ZL, Liu JQ, Jiang S and Miao XY: Identification of CD146 expression, angiogenesis, and lymphangiogenesis as progression, metastasis, and poor-prognosis related markers for gallbladder adenocarcinoma. Tumour Biol 33: 173-182, 2012.

30. Jiang T, Zhuang J, Duan H, Luo Y, Zeng Q, Fan K, Yan H, Lu D, Ye Z, Hao J, et al: CD146 is a coreceptor for VEGFR-2 in tumor angiogenesis. Blood 120: 2330-2339, 2012.

31. Aldovini D, Demichelis F, Doglioni C, Di Vizio D, Galligioni E, Brugnara S, Zeni B, Griso C, Pegoraro C, Zannoni M, et al: M-CAM expression as marker of poor prognosis in epithelial ovarian cancer. Int J Cancer 119: 1920-1926, 2006

32. Livak KJ and Schmittgen TD: Analysis of relative gene expression data using real-time quantitative PCR and the 2(-Delta Delta C(T)) method. Methods 25: 402-408, 2001.

33. Weddell JC and Imoukhuede PI: Quantitative characterization of cellular membrane-receptor heterogeneity through statistical and computational modeling. PLoS One 9: e97271, 2014.

34. Kornbrot D: Statistical software for microcomputers: SigmaPlot 2000 and SigmaStat2. Br J Math Stat Psychol 53: $335-337,2000$

35. Wu GJ, Wu MW, Wang SW, Liu Z, Qu P, Peng Q, Yang H, Varma VA, Sun QC, Petros JA, et al: Isolation and characterization of the major form of human MUC18 cDNA gene and correlation of MUC18 overexpression in prostate cancer cell lines and tissues with malignant progression. Gene 279: 17-31, 2001.

36. Liu WF, Ji SR, Sun JJ, Zhang Y, Liu ZY, Liang AB and Zeng HZ: CD146 expression correlates with epithelial-mesenchymal transition markers and a poor prognosis in gastric cancer. Int J Mol Sci 13: 6399-6406, 2012

37. Oka S, Uramoto H, Chikaishi Y and Tanaka F: The expression of CD146 predicts a poor overall survival in patients with adenocarcinoma of the lung. Anticancer Res 32: 861-864, 2012.
38. Sato A, Torii I, Okamura Y, Yamamoto T, Nishigami T, Kataoka TR, Song M, Hasegawa S, Nakano T, Kamei T and Tsujimura T: Immunocytochemistry of CD146 is useful to discriminate between malignant pleural mesothelioma and reactive mesothelium. Mod Pathol 23: 1458-1466, 2010.

39. Kristiansen G, Yu Y, Schlüns K, Sers C, Dietel M and Petersen I Expression of the cell adhesion molecule CD146/MCAM in non-small cell lung cancer. Anal Cell Pathol 25: 77-81, 2003.

40. Chen W, Zhang HL, Jiang YG, Li JH, Liu BL and Sun MY: Inhibition of CD146 gene expression via RNA interference reduces in vitro perineural invasion on ACC-M Cell. J Oral Pathol Med 38: 198-205, 2009.

41. Zeng Q, Li W, Lu D, Wu Z, Duan H, Luo Y, Feng J, Yang D, Fu L and Yan X: CD146, an epithelial-mesenchymal transition inducer, is associated with triple-negative breast cancer. Proc Natl Acad Sci USA 109: 1127-1132, 2012.

42. American Cancer Society. Cancer Facts \& Figures 2012. Atlanta: American Cancer Society, 2012.

43. Takahashi Y, Kitadai Y, Bucana CD, Cleary KR and Ellis LM: Expression of vascular endothelial growth factor and its receptor KDR, correlates with vascularity, metastasis, and proliferation of human colon cancer. Cancer Res 55: 3964-3968, 1995.

44. Lu Y, Xu Q, Zuo Y, Liu L, Liu S, Chen L, Wang K, Lei Y, Zhao X and $\mathrm{Li} \mathrm{Y}$ : Isoprenaline/ $\beta 2-\mathrm{AR}$ activates Plexin-A1/VEGFR2 signals via VEGF secretion in gastric cancer cells to promote tumor angiogenesis. BMC Cancer 17: 875, 2017.

45. Paley PJ, Staskus KA, Gebhard K, Mohanraj D, Twiggs LB, Carson LF and Ramakrishnan S: Vascular endothelial growth factor expression in early stage ovarian carcinoma. Cancer 80 : 98-106, 1997

46. Shen GH, Ghazizadeh M, Kawanami O, Shimizu H, Jin E, Araki T and Sugisaki Y: Prognostic significance of vascular endothelial growth factor expression in human ovarian carcinoma. Br J Cancer 83: 196-203, 2000.

47. Premalata CS, Umadevi K, Shobha K, Anurekha M and Krishnamoorthy L: Expression of VEGF-A in epithelial ovarian cancer: Correlation with morphologic types, grade and clinical stage. Gulf J Oncolog 1: 49-54, 2016.

48. Duncan TJ, Al-Attar A, Rolland P, Scott IV, Deen S, Liu DT, Spendlove I and Durrant LG: Vascular endothelial growth factor expression in ovarian cancer: A model for targeted use of novel therapies? Clin Cancer Res 14: 3030-3035, 2008.

49. Yan H, Zhang C, Wang Z, Tu T, Duan H, Luo Y, Feng J, Liu F and Yan X: CD146 is required for VEGF-C-induced lymphatic sprouting during lymphangiogenesis. Sci Rep 7: 7442, 2017.

50. Nodomi S, Umeda K, Saida S, Kinehara T, Hamabata T, Daifu T, Kato I, Hiramatsu H, Watanabe KI, Kuwahara Y, et al: CD146 is a novel marker for highly tumorigenic cells and a potential therapeutic target in malignant rhabdoid tumor. Oncogene 35: 5317-5327, 2016.

51. Tsiolakidou G, Koutroubakis IE, Tzardi M and Kouroumalis EA: Increased expression of VEGF and CD146 in patients with inflammatory bowel disease. Dig Liver Dis 40: 673-679, 2008. 